\title{
Teaching Blindfolded: One Teacher's Struggle to Meet the Needs of Her Somali Students in the Era of High Stakes Testing and Scripted Curriculum
}

\author{
Teresa Kruizenga ${ }^{1, *}$ \\ ${ }^{1}$ Minnesota State University, Mankato, 313 Armstrong Hall, Mankato, MN 56001, USA \\ *Correspondence: Minnesota State University, Mankato, 313 Armstrong Hall, Mankato, MN \\ 56001, USA. Tel: 1-507-389-1777 E-mail: teresa.kruizenga@mnsu.edu
}

Received: August 13, 2016 Accepted: August 24, 2016 Published: November 13, 2016

doi:10.5296/ije.v8i4.9886 URL: http://dx.doi.org/10.5296/ije.v8i4.9886

\begin{abstract}
The following case study looks at one teacher's struggle to meet the needs of her Somali students' in the era of high stakes testing and scripted curriculum. It documents the pressure on teachers and students to improve the average school state mandated test scores and to ignore the intellectual and vocational resources of the families in the community (Gonzalez et al., 1995). Consequently, more and more schools are adopting a prescribed curriculum with scripted lessons to replace inquiry lessons. This study discusses how this curriculum adoption often forces teacher to ignore students' needs and cultural background and teach to the test.
\end{abstract}

Keywords: Somali, Immigrants, High stakes testing, Scripted curriculum 


\section{Introduction}

When Isra Ali (pseudonym) came to Minnesota at age five, she had learned much in her brief five years. Isra is already fluent in two languages and has traveled to several different countries. These opportunities provided her with several lived learning experiences. All these experiences did little to prepare her for what she would encounter in a public school in Minnesota. For example, she did not know to step on the foot bar to get water from the lavatory sink at her school, or to store textbooks in a locker rather than carrying them all home every day.

Isra is part of a population of about 30,000 Somali refugees in Minnesota. According to the Minnesota Demographic Center there was an estimated 5,734 Somali children enrolled in Minnesota schools during the 2004-2005 academic year. 84\% are located within the Twin Cities. According to the Minnesota Department of Education there were 14, 876 Somali students in 2012 identified as English Language Learners. This number increased to 19, 126 in the fall of 2014. The number of Somalis resettled in the state has grown immensely. These numbers reflect an immediate urgency for schools to prepare for the unique strengths and learning opportunities that ought to be in place for the changing population within our schools. High quality schooling experiences are essential for children who come to the United States as immigrants or refugees.

Some educational theorists have argued that to better support learning among children from nondominant backgrounds greater attention needs to be paid to the cultural knowledge and resources children bring to learning. Others state that educators should rely upon cultural knowledge and experience to create a space where schools can bridge 'everyday' knowledge with 'scientific' knowledge. Despite the differences both pedagogical approaches are grounded in students' cultural backgrounds and everyday knowledge in hopes of creating meaningful learning opportunities which shape and transform academic knowledge.

Recent focus on the reauthorization of the No Child Left Behind (NCLB) law has turned attention, once again, directly to student test scores, which report only some cognitive gains. In fact, in revisiting the No Child Left Behind it appears that legislation have dug in their heels to say that annual tests should remain mandatory. Since NCLB became federal law teachers and principals report that NCLB has had a direct impact on the manner in which they teach children. The pressure on school administrators, teachers and students to improve average school scores on norm referenced, short answer multiple choice tests has created a widespread tendency to ignore high order skills (since the tests elicit facts) and to put classroom emphasis on preparing students to take tests, especially at the elementary level and more specifically in low income schools where drill has always been a more prevalent form of instruction than investigation has been. Thus, more and more schools are reporting focusing much more time on test preparation, using scripted curriculum materials and spending greater amounts of time on whole group direct instruction versus small group inquiry-based instruction. The researcher hold's that instruction must be linked to students' lives and that the details of effective pedagogy should be linked to local community contexts. This paper is an attempt to better understand the experiences of Somali students within one 
urban Upper Midwestern public elementary school. In this paper, I address the following questions: How does one classroom in Eastside School (pseudonym) accommodate Somali students? What are the academic implications of learning and teaching in this environment?

\subsection{Somalis}

Somalis are an ethnic group that are almost entirely Muslim (Collet 2007; Masny 1999; Wilder 2000). Somalia is located in East Africa and is a little smaller than the state of Texas. Most of Somalia is rural and nearly $80 \%$ of the people are pastoralists, agriculturalists, or agro pastoralists. The vast majority of people are ethnic Somalis who practice Islam and speak dialects of Somali (Putman, 1993). Their society is clan based with most families having many children and include extended family members in the household (Masny,1999). Oral language is the main form of communication with no written language until 1972 (Crabb, 1996).

Somalis were forced to leave their country due to influences of colonialism, communist military dictatorship, and religious persecution. Years of oppression eventually drove the Somali people to war. The civil war had a devastating effect with an estimated 400,000 people killed, or died of famine or disease; almost $45 \%$ of the people were displaced inside the country or fled to other countries (Putman, 1993). Desperate for a place of peace and prosperity Somali refugees flocked to Minnesota. Due to word of mouth, Minnesota was proclaimed as the place of good employment, good schools, excellent refugee services, and most importantly the hope of being reunited with loved ones.

Thus, Minnesota became the destination of hope for many Somali refugees. According to Minnesota Public Radio, "Minnesota saw its third largest influx of immigrants in a quarter century in 2004, with immigrants from Somalia leading the pack.” In all, 11,708 legal immigrants came to Minnesota in 2004, according to Department of Homeland Security date released by the State Demographic Center. That put the state at $16^{\text {th }}$ nationally, but it is first in the number of Somali immigrants. Ohio was a distant second (Condon, 2006, as cited in MPR News Q retrieved September 24, 2009). There is, however, a tremendous gap between Minnesota educators and the Somali immigrant students. With the sudden influx of Somali children entering the schools in Minnesota it is imperative that we take the first steps toward understanding and implementing a culturally relevant curriculum that meets the needs of these students. In the words of Mohamed Fared (2004), “ Learning about another culture is a life-long undertaking. The first step in this rewarding journey is to contrast elements of one's own culture to the other" (p. viii). This paper is an attempt to take those " first steps" to learn about the Somali culture and the experience of Somali children attending schools in the US.

\subsection{The 'Funds of Knowledge’ Approach}

Funds of knowledge have been defined as "the essential cultural practices and bodies of knowledge and information that households use to survive, to get ahead, or to thrive” (Moll, Amanti, Neff \& Gonzalez, 1992, p.21). Moll et all (2001) refer to the historical accumulated and cultural developed bodies of knowledge and skills essential for household or individual functioning and well being (p. 133). 'Funds of knowledge" are drawn from socio-cultural 
contexts and work to secure individual and family wellbeing. "The basic premise has been that classroom learning can be greatly enhanced when teachers learn more about their students and about their students' households” (Gonzalez, 2001 p. 116). Norma Gonzalez et. Al. (2005), have developed an approach using 'funds of knowledge' with marginalized communities to transform their household resources into recourses for teaching. The aim of the 'funds of knowledge' approach is to expand the classroom walls and provide classroom instruction that exceeds the rote-like 'drill and kill' lessons that children commonly encounter in schools.

Gonzales et.al. (2005) highlights the point that there is no cookie-cutter recipe that will work equally well in all the school sites. The term funds of knowledge is being used in anthropologically oriented educational projects to characterize the everyday knowledge that members of a community have and can be studied by educators and used in the development of curriculum. In a curriculum development project in Arizona that has used this orientation, teachers collaboratively explored the intellectual and vocational resources of the families in the community and used this knowledge as a base for curriculum building (Gonzalez et.al., 1995). Teachers made home visits as part of a team to observe the activities of the household and returned to the university for discussions about their observations with anthropologists and educators. They also explored how they could build on the family and community 'funds of knowledge' to create lessons for their classrooms. Moll argued that much of the knowledge and skills of families, including elements of their daily lifestyle, can yield legitimate content relevant to school curricula. Hatttam, Lucas, Posser, and Sellar (2007) draw on the 'funds of knowledge' to use students' 'funds of knowledge' to create new curriculum that values the roles, behaviors and skills of students as a resource for student engagement and success.

\subsection{The Reformation of Education}

With the signing of the No Child Left Behind law (NCLB) in 2002, national officials mandated that schools show evidence that they are meeting the needs of all their students. Particularly, the political lens has focused on children who have been labeled as 'at risk, 'disadvantaged', and 'minority'.

The federal government in an attempt to minimize the achievement gap has made attempts at standardizing the curriculum, mandating high stake testing to measure student growth, imposing ramifications to schools who fail to demonstrate academic progress, providing funding for alternative schooling opportunities, such as charter schools. These mandates first imposed by President Bush's No Child Left Behind provided data that had not been available in the past; student growth and test scores now can be desegregated by race, class and ability level. On July 24, 2009, President Obama and Education Secretary Arne Duncan announced what they believe to be "the great equalizer in America, no matter what your zip code, "(Remarks by Educational Secretary Arne Duncan retrieved March 11, 2010), the Race to the Top fund. School districts compete for a portion of the $\$ 4.35$ billion dollars made available for reform and innovation. Under Race to the Top guidelines, states seeking funds will be pressed to implement four core-interconnected reforms; (a) to reverse the pervasive 
dumbing-down of academic standards and assessments by states; (b) to close the data gap; (c) to boost the quality of teachers and principals, especially in high-poverty schools and hard-to-staff subjects; and (d) to turn around the lowest-performing schools (Duncan, 2009).

Thus, Race to the Top is attempting to build on what NCLB has put into place. Both NCLB and Race to the Top acknowledge the academic discrepancy between White middle class students and those students who are often marginalized within the classroom. The goal to create a public school system that is our society's great equalizer is an honorable one. However, whose knowledge is being privileged in the public school and how is the testing craze perpetuating and maintaining the status-quo? According to the U.S. Department of Education (2005), over 37\% of K-12 students are culturally, linguistically, and ethically different from the dominant U.S. culture. I addition the United States Census Bureau recently released population projections showing that non-Hispanic whites will no longer be the majority population in 2042 (US Census Bureau 2008b); Roberts 2008). Recent reports put the teaching population at $90 \%$ White, female, and middle class. If only $10 \%$ of teachers are linguistic and ethnic minorities and almost $40 \%$ of students are linguistic and ethnic minorities, it is clear that many thousands of students are being taught by teachers who have little or no background in the children's culture, language, traditions and history. Whichever ethnicity they come from, teachers are finding themselves in schools where their own experiential background differs from that of their students (Grand\& Gomez, 2001; Taylor, 2000; Nieto 2000). Teachers who are born in the United States and grow up in some strata of the middle class may have little in common with students of the same ethnicity who are immigrants or who grow up in lower socioeconomic status situations (Zeichner, 1993, in Taylor, 2000). In discussing the use of multicultural literature in teaching, Taylor (2000) suggests, “Considering the mismatch between students' and teachers' diversity, teachers may want to sensitize and expose their students and themselves to multiple perspectives and cultures of U.S. society” (p.25).

The most difficult aspects of this resettlement for Muslim families is following Islam in a predominantly Judeo-Christian society (Berns McGown, 1999, p. 101). Tensions are particularly acute because their family and community often espouse beliefs that are in direct conflict with the US adolescent cultures of, for example, dating, sexual practices, entertainment, and dress. Schools are the key sites of this tension and often a place of rapid assimilation (Olneck, 2003) as opposed to a more culturally thoughtful adaptation process (Bhatia \&Ram, 2004; Gibson, 1988). Thus, the Somali bring about a unique perspective that other immigrant groups do not.

In addition to the discrepancies between the teacher and student cultural mismatch more and more children are receiving a second-class education. The pressures of standardized testing on curriculum have decreased instruction in social studies, science, writing, problem solving and analytical reasoning; they are felt from kindergarten, where the pressure is to teach quantifiable math and reading skills and to prepare children for an educational career of "bubble test" taking, to high school, where minimum competencies for graduation may also mark the upper limits of instruction. This educational philosophy is intensified in urban schools where children from disadvantaged backgrounds are more likely to follow a scripted 
curricular program that often deskill and dehumanizes the teacher and the student.

\subsection{The Study}

This ethnographic case study follows one first grade teacher and her 16 students for 6 hours a day for 6 weeks. The classroom teacher is showcased because her stories illustrate numerous insights into how the school experience can provide a bridge or a barrier for teaching and learning in the era of high stakes testing, prescribed and scripted curricula, in relation to Somali children within her classroom. As a case, she challenges recent school reform initiatives that see Somali students mainly through the deficit lens. It is revealed that the teacher becomes frustrated when prior family and community knowledge ('funds of knowledge') is banned from being utilized to make meaningful learning connections within the classroom due to strict district mandates in order to teach to the test.

In light of the overview of literature on funds of knowledge and federal mandates on education, and the experiences revealed within this first grade classroom there is a need for particularizing the experience of attending an elementary school as a recently resettled first grade immigrant with limited English proficiency. Equally important is to situate those experiences in a way that underscores the realization that many factors combine to make a successful school experience. To further an understanding about how teacher and curriculum connect around issues of teaching and learning for immigrant first graders, the following question focusing on one first grade classroom will be explored:

- What are the experiences of 16 first graders and their teacher as the teacher is mandated to teach to a prescribed scripted curriculum that runs counter to the teacher's belief to seek wide, deep and thoughtful engagement in the learning process for her immigrant students in an urban elementary school setting, particularly her Somali students?

\section{Methodology}

The research is interpretive and qualitative in nature. The data for this paper came from a small ethnographic study carried out within an elementary school, the Eastside Elementary School (pseudonym), located in an Upper Midwestern urban community. In this study, the researcher examined one first grade classroom teacher and her 16 students' dialogic reflections, observations of teaching and their interactions within the classroom using an inquiry approach similar to Moll, Amanti, Neff, and Gonzalez' (2005) funds of knowledge for 6 hours a day for 6 weeks. The theoretical proposition that is the foundational framework for this inquiry is that the participant who (a) attempt to get to know children and their families through inquiry and authentic relationship building; (b) examine current values and norms in public schools; and (c) abandon culturally relevant strategies and practices to take up a structured/scripted curriculum in the context of a urban setting. This theoretical proposition was applied as the researcher investigated the following question:

What are the experiences of 16 first graders and their teacher as the teacher is 
mandated to teach to a prescribed scripted curriculum that runs counter to the teacher's belief to seek wide, deep and thoughtful engagement in the learning process for her immigrant students in an urban elementary school setting?

\subsection{Data Collection}

Ethnography produces three kinds of data: quotations, descriptions, and excerpts of documents (Genzuk, 2003). Because the researcher was focused on capturing the teacher's story as well as the students' point of view the following types of data were collected: field notes, students' dialogic conversations/reflections (audio and video recorded), video recordings of class interactions, video recordings of teacher teaching and audio recording of pre and post interview with teacher, pupil and pupil work (i.e., workbook pages, sample writing, etc.)

Miles and Huberman (1994) describe analyzing data as data, which relies primarily on ethnography as "social anthropology" (p. 50). They state that researchers using this approach seek to provide detailed descriptions across multiple data sources. While useful and important ideas can emerge during analysis across multiple data sources, the most powerful insights come from a rigorous analysis of systematically collected data (Fetterman, 2010). This analysis started with discussions with the first grade teacher at the end of each day as we attempted to reflect and make meaning of the teacher/pupil interactions, pupil learning episodes, pupil learning and pupil reactions. In addition the researcher shared open-coded interviews and dialogic interactions with teacher and student transcripts with the teacher to invite her thoughts and ideas of emerging themes and important topics. The researcher cross-referenced these themes and topics with the open-coded field notes created by the researcher. Together the researcher and first grade teacher sorted and discussed themes and topics that were revealed - to gain insights into how one first grade teacher conceptualized teaching to a prescribed, scripted curriculum in the era of high-stakes testing and how the teacher and her students made sense of their experiences, specifically her Somali students.

Examining one first grade teacher and students' experiences and reflections provided an opportunity to analyze and interpret complex facets of learning to teach in an urban school setting. Having a larger sample would have provided the researcher a greater pool of stories to interpret, but it would have made it much more difficult to explore these experiences in-depth. Ethnographic methodology allowed the researcher to become a participant-observer who "lived with and lived like those who are studied" (Van Maanen, 1996, p. 264). This insider view provided rich insights in to how mandated prescribed curricula impacted one teacher's teaching and how her students made sense of this teaching and learning experience.

It is not the intention of this study to present a "silver bullet." The goal is to give rise to the voice of one elementary teacher and her 16 first grade students' experience. Paying close attention to these voices makes it possible to uncover the social, structural, and cultural bases of choices and actions that privilege some learners in the class while disenfranchising others. Their story gives us some new stories to consider in teacher education, and some new insights. The goal is to "divulge the story from the 'actors' point of view” (Erickson, 1986, p.119). 


\subsection{The Teacher, The Classroom and The School}

In this section, I introduce the classroom, school and teacher. This is followed by a section in which I describe the teachers' beliefs about her teaching philosophy and the school's curriculum. Sixteen busy six and seven year old children comprise the classroom, nine boys and seven girls. Seven children within the classroom state that Somali is the language spoken in their home. Two of the seven Somali speaking children were born in the US. All seven children state that they did not speak English before entering school. This classroom community is nestled within a larger community of 296 children enrolled in prekindergarten thru sixth grade. The district reports that $91 \%$ of the children attending this school are enrolled in a free and reduced priced lunch program. 67\% of the children attending this school are limited English proficient: 31.12\% are English speaking; 11.19\% Spanish; 29.72\% Somali: and $10.14 \%$ other (obtained from the school district's website).

Sue (pseudonym), who appears to be White, middle aged, first grade teacher at Eastside Elementary has been teaching within the school district for 15 years. She came to teaching as a second career, thus, a career changer. Possessing substantial life experience resulting from previous career (i.e., farming, Exercise and Fitness Management Degree), and raising two children, provides Sue with important assets, such as maturity and expertise to her teaching. Children and adults alike are drawn to Sue's extremely warm, positive manner. You will find Sue greeting each child individually outside the classroom door each morning and children often respond with a warm hug in return. Sue appears to be well liked by the children, and staff alike; however, it is Sue's passion and commitment to education that is most noticeable when you meet her. One example, of her professional commitment to the field of education is how much time and money she has invested in professional development. After she received her initial teaching licensure through an alternative teacher licensure program and securing her job as a teacher within the district, she has received a Master's Degree in Education, a Master's Degree in Literacy, completed Reading Recovery Training and just recently submitted the required paper work for National Board Certification. Such certification, which requires teachers to put together a portfolio and to complete a series of exercises and activities designed to test their knowledge of material for their particular field, takes well over a year and is far more difficult to obtain than state licensure. Higher percentages of Board certified teachers signify a higher quality teaching staff. The initial Reading Recovery training is a yearlong commitment in which teachers enroll in two graduate-level courses, one in the fall and one in the spring, taught by a certified Reading Recovery teacher leader. Professional development is an essential part of Reading Recovery. After the initial year of instruction, teachers engage in ongoing professional development called Continuing Contact. There are typically six sessions per year, which are theoretical in nature, helping teachers to better understand why they do what they do. Similar to the training year, a one-way mirror is utilized, allowing teachers to observe one another working with children. Sue's commitment to quality education is clearly demonstrated in her continued pursuit of higher education. One key finding is that Sue stressed that highly qualified teachers need to continually learn and use that knowledge to help his or her students succeed. The data in this section will show how Sue's qualifications and commitment are valuable forces in their education. 
TK (researcher): $\quad$ Can you tell me what drives you to continue your pursuit of knowledge within your field?

S (Sue): I think teacher knowledge is considered to be as a key factor in the success of my students' learning. I need to be on top of my game...so to speak. I just don't mean 'what' I know...like math, or history...but how is the best way to deliver instructions my students (T. M. Kruizenga, January 2013).

TK: $\quad$ Other than seeking new degrees and professional development what else do you do to improve your teaching?

S: I believe that you can't have too many teachers in one room. If I can team teach with the ELL teacher or the literacy coach I will. They are always welcome to join my classroom. I think as a team we can meet the needs of the students better. I learn from many different people and they all help to improve my practice.

This quote both reflects Sue's commitment to teaching and learning within her classroom and her willingness to engage in cooperative, reflective and critical practice.

The interviews revealed that Sue has strong opinions about teaching/learning and has her own way of interacting with her students. For example, Sue said that she tries hard to find the strengths in each child's learning styles and builds off from those strengths. While this may not be a common trait or style for all the teachers at the school, the message to students is clear: this teacher is going to find what they do well and build on this.

In the following quote, Sue explains how this approach has made a difference with the students in her class:

S: Jennifer had a rough time at the beginning of the year. She had a hard time following direction and often disrupted the other students' learning (T. M. Kruizenga, January 2013).

TK: $\quad$ If she was so disruptive how were you able to use this approach?

S: $\quad$ If she even did the slightest movement towards a behavior...I praised her. I try to understand where each child is coming from and show them he same respect that I would hope someone would treat me.

TK: $\quad$ How do you show your students respect?

S: $\quad$ Well...many of my students come from another culture and speak another language. I try to learn and use their language in the classroom as much as possible. I also try to help the students learn each other's language and culture as well.

TK: $\quad$ How do you see this helping your students?

S: $\quad$ Some of my students at the beginning of the year are uncomfortable with school and are quiet and more ... well . . . withdrawn. I want them to know 
their language and culture is welcomed in this classroom and that I want to learn from them just as much as they learn from me. They teach me how to say words in their language and we practice greeting each other in their language.

TK: $\quad$ Do you believe that this has a direct impact on academic performance?

S: $\quad$ Well...it does help them to connect what they know to the new information presented in class. But, does it help them on the MCAs? I'm not sure. I guess it could. I mean ... . if we make a connection with their home language and culture maybe they'll be more likely to remember the information.

Another strategy that Sue uses to guarantee her students' educational success is to address the cultural differences in the classroom openly. To an outsider, these cultural issues may seem trivial, but Sue takes them seriously. It may not have a direct impact on academic performance, but such cultural acceptance has an impact on the students' self confidence, self-image and self-esteem.

Sue identifies how cultural issues bump up against prescribed curriculum in the school for many other students. In the following quote, Sue explains her opinion about the fact that the school district is mandating more and more of what can be taught and how it is to be taught.

S:

Sometimes I get so frustrated because I have spent all this time and energy learning teaching strategies that I know are effective for students . . . research supported and proven . . . but I am being told that I must follow the script. No matter who my students are or what is happening at the time (T. M. Kruizenga, February 2013).

TK: $\quad$ Do you ever stray?

S: $\quad$ This is our first year with this program and we are to follow it to a ' $\mathrm{t}$ '.

I will give it a year. After all, it is put together by researchers . . . maybe they know something I don’t. But . . . sometimes I feel that the district is asking me to teach with my hands behind my back and blind folded.

TK: $\quad$ What do you mean by that?

S: $\quad$ Like ... I have spent all this time and energy learning about how to be the best teacher ... and . . . and I'm told that what I know about teaching . . . and about my students . . . . and their families is not important or needed.

This excerpt illustrates the struggle Sue has with using the scripted curriculum. These data contribute to the literature cited previously (e.g., Gonzalez et.al. 2005, \& Hattam, Lucas, Posser, and Sellar, 2007) indicating that there is no cookie-cutter recipe that will work equally well in all school sites. Sue's inclination is to draw on the 'funds of knowledge' to create new curriculum that values the roles, behaviors and skills of students within her classroom, but she feels that her hands are tied. On a separate occasion, Sue told me that if she wants to engage in instruction that exceeds the rote-like 'drill and kill' lessons it needs to be done as an extra or add on activity. She also shared with me that doing these extra 
activities are often frowned upon as administration is worried that you are then not teaching the prescribed curriculum.

\subsection{Classroom Observations}

To get a sense of the students and teachers interacting with curriculum throughout the day, I took on the role of co-participant within the classroom. Through this co-participant role I made a couple of observations: one being the impact of the restrictive setting, created by the prescribed curriculum, placed on teacher and students. Sue began her math lesson in the same manner each day I was in the classroom. As you looked down the hall, you could see the other teachers, regardless of the grade being taught, teaching math in this same style as well. Teachers are standing at the front of the room next to the overheard projector, screen is pulled down and math lesson is being projected onto the screen. The teacher hushes the students, directs them to their desk as math workbooks are handed out. The math workbook is completed together as they work through the problems that are assigned to them that day.

One day while I was in the classroom Sue asked if I would give extra assistance to three students in the back. These three students are English language learners (two Somali speakers and one Spanish speaker) and could benefit from some additional support. The focus of the math lesson was on learning to count money. The workbook page was filled with different types of candy. Next to each candy type was a dollar amount. The teacher would ask the children to determine the amount of money needed to purchase certain types and combinations of candy. "How much money would you need to buy two gum balls and one jawbreaker?” A few hands shot in the air. A little boy that I was assisting leaned in to whisper in my ear, " what is this?” He was pointing at the gumball machine located front and center in his workbook. While the lesson went on, I explained to the children that I was tutoring the workings of a gumball machine. We also discussed the difference between gumballs and jawbreakers (they looked identical in the illustration provided). Once the students understood what was being asked of them and what each illustration represented, they eagerly began their work. However, at this time the lesson was over, and they were to return the workbook to its home. The girl that I was working with refused. She kept working despite her teacher demanding that it was time to move on. The boy in the group dropped his head to his desk in frustration. As I tried to sooth each child, with offers to help them finish at a later time, the boy threw his workbook across the room and screamed, "No!”.

Later Sue expressed her frustration with this scene. She shared with me that she knew exactly why the students acted the way that they did, but she felt unable to address their needs. The students forced to use a curriculum that had so many cultural differences left the students feeling inferior and stupid. Tears welled up in Sue's eyes as she shared with me how this breaks her heart. In the past, she would have never taught in this manner. However, all teachers were given this curriculum and instructed to follow the script provided and teach in this exact manner. Teachers are also told what page they are to be on at certain times in the year. The reason for this is to provide a consistent educational experience across classrooms and schools. Thus, students who move often will not miss important aspects of the curriculum. She also shared with me that she would have set up a classroom store where students could 
actually purchase items in the classroom and practice in a more authentic manner with items that all the children were familiar with.

The above observation demonstrates how teaching to the test and the curriculum prohibits the teacher from implementing a curriculum that draws from socio-cultural contexts. Students are left feeling frustrated and unsuccessful. Moreover, teachers feel like "failures" when they are forced to teach, "blind folded" and ignore the needs of their students (personal conversation with Sue).

\section{Conclusion}

It is important to theorize about Sue and her first grade classroom experiences carefully. There is always the risk that we misrepresent the teacher and the students. For example, the achievement gap reported by federal mandated high stakes testing present a bleak picture of urban schools and help to perpetuate a deficit perception of marginalized students (i.e., students achieve less, attain less education, encounter less success), due to home environments that do not foster educational support. In our present test crazed era, are we reinforcing these deficit perceptions of marginalized students? The data presented should challenge the deficit discourse so often associated with immigrant students. The information uncovered in this study shows that while the first grade students struggled with the prescribed curriculum, this did not mean that they were unable or unwilling to achieve success. The curriculum presented failed these students on many levels. First, these students were not given equal access to the curriculum being presented. Secondly, the teacher and students were deprived of the opportunity to engage in an enriched learning environment where multiple voices, languages, cultures and ways of knowing could prove to be the impetus of study each day.

Because of NCLB a shift in curriculum and pedagogy has swept the nation. As a direct result teachers are encouraged and mandated to desensitize their teaching while enacting principles of automation to teaching. Our work as teachers is not one of 'manufacturing' smart children who have much factual knowledge. Rather it is helping children find that the adventure of learning is an enjoyable and motivating lifetime journey. Had the students been presented the content in a context that was relevant to their lived experience the academic and social emotional outcome might have been much different than the lessons I observed.

Removing the need for skill, judgment, or initiative is contradictory to the teaching profession; busy work is not our specialty, meaningful work is. Anyone would acknowledge that Sue had the relevant credentials as well as the experience needed to be a successful elementary teacher. Nevertheless, the mandated curriculum put in place as a direct result of high stakes testing did not allow Sue to tap into her areas of expertise. She was often forced to ignore students' needs, to teach to the test. Although many factors combine to make a successful school, most people would agree that quality teachers are among the most important requirements for success, especially when success is defined by the ability of the school to raise the achievement of its students. Eastside elementary is fortunate to have Sue 
and many other teachers who are committed to teaching and learning. However, this dedicated staff is left feeling deskilled and dehumanized at the end of the teaching day. Fund of knowledge suggests educational experiences should directly connect with the cultural and linguistic talents, and realities that children bring with them to the classroom, rather than making learning an exercise in standardizing experiences and assimilating children into mainstream discourse and culture. Schools and communities must work together to create a curriculum and instructional practices that affirms all children, and connects their cultural reality to their learning experiences.

\section{Resources}

Baker, C. (2000). The care and education of young bilinguals. New York: Multilingual Matters LTD.

Coffey, A. (1996). Making sense of qualitative data: Complementary strategies. Thousand Oaks: Sage Publication.

Coleman, M. \& Ganong, L. (Ed.). (2004). Handbook of contemporary families: Considering the past, contemplating the future. Thousand Oaks, CA: Sage.

Erickson, F. (1986). Qualitative methods in research on teaching. In M. Wittrock (Ed.), Handbook of research on teaching ( $3^{\text {rd }}$ ed., pp. 119-161). New York, NY: Macmillan

Farid. M. (2004). Accommodating and educating Somali students in Minnesota Schools. St. Paul: Hamline.

Fetterman, R. (2010). Ethnography step by step ( $3^{\text {rd }}$ Ed. ). Los Angeles: Sage

Genzuk, M. (2003). Tapping into community funds of knowledge. In P. Foundation (Ed.), Effective strategies for English language acquisition: A curriculum guide for the development of teachers, grades kindergarten through eight, pp. 111-119. Los Angeles: Los Angeles Annenberg Metropolitan Project/ARCO Foundation

Gonzalex, N. M. (2005). Funds of knowledge. New Jersey: Lawrence Erlbaum Associates.

Gonzalez, N. (1995). Processual approaches to multicultural education. Journal of Applied Behavioral Science, 31(2), 234-244. http://dx.doi.org/10.1177/0021886395312008

Gonzalez, N. (2005). Beyond culture: The hybridity of funds of knowledge. In N. M. Gonzalez, Funds of Knowledge (pp. 29-46) Mahway, New Jersey: Lawrence Erlbaum Associates.

Grant, C. (2001). Journeying toward multicultural and social reconstructionist teaching and teacher education. In C. \& Grant, Making school multicultural: Campus and classroom (pp. 3-16). Columbus, OH: Merrill.

Maanen, V. (1996). Ethnography. In A. Kuper and J. Kuper (eds.), The social science encyclopedia ( $2^{\text {nd }}$ Ed.), 263-265. London: Routledge 
Masny, D. (1999). Weaving multiple literacies: Somali children and their teacher in the context of school culture. Language, Culture and Curriculum, 72-93. http://dx.doi.org/10.1080/07908319908666570

Miles, M., \& Hubberman, A. M. (1994). Qualitative Data Analysis (2 ${ }^{\text {nd }}$ Ed.). Thousands Oaks, CA; Sage.

Moll, L. A. (1992). Funds of knowledge for teachers: Using a qualitative approach to connect homes and classrooms. Theory to Practice, 132-141. http://dx.doi.org/10.1080/00405849209543534

Moll, L., Amanti, C., \& Gonzalez, N. (2005). Funds of knowledge: Theorizing practices in households, communities, and classrooms. Routledge, New York.

Nieto, S. (2000). Affirming diversity. Boston: Allyn \& Bacon.

Olneck, Michael E. (2003). Immigrants and education in the United States. In James A. Banks \& Cherry A. McGee Banks Eds.), Handbook of Research on Multicultural Education (pp. 381-403) San Francisco: Jossey-Bass

Putman, Diana B. (1993). The Somalis: Their history and culture. CAL refugee fact sheet series, 9, 1-22.

Wilder Research Center. (2000). Speaking for themselves: A survey of Hispanic, Hmong, Russian, and Somali immigrants in Minneapolis-St. Paul. Retrieved from www.wilder.org/research/reports

Zeichner, K. (1993). Educating teachers for diversity. East Lansing, MI: National Center for Research on Teaching and Learning.

\section{Copyright Disclaimer}

Copyright for this article is retained by the author(s), with first publication rights granted to the journal.

This is an open-access article distributed under the terms and conditions of the Creative Commons Attribution license (http://creativecommons.org/licenses/by/3.0/). 